\title{
Hemispheric Brain Injury and Behavioral Deficits Induced by Severe Neonatal Hypoxia-Ischemia in Rats Are Not Attenuated by Intravenous Administration of Human Umbilical Cord Blood Cells
}

\author{
SIMONE de PAULA, AFFONSO SANTOS VITOLA, SAMUEL GREGGIO, DAVI DE PAULA, PÂMELA BILLIG MELLO, \\ JEREMIAH MISTRELLO LUBIANCA, LÉDER LEAL XAVIER, HUMBERTO HOLMER FIORI, \\ AND JADERSON COSTA DACOSTA
}

\author{
Laboratório de Neurociências [S.P., A.S.V., S.G., D.P., L.L.X., J.C.D.], Centro de Memória [P.B.M.], Centro de Terapia Celular [J.M.L.], \\ Departamento de Pediatria [H.H.F.], Pontifícia Universidade Católica do Rio Grande do Sul, Porto Alegre, RS 90610-000, Brazil
}

\begin{abstract}
Neonatal hypoxia-ischemia (HI) is an important cause of mortality and morbidity in infants. Human umbilical cord blood (HUCB) is a potential source of cellular therapy in perinatology. We investigated the effects of HUCB cells on spatial memory, motor performance, and brain morphologic changes in neonate rats submitted to HI. Seven-day-old rats underwent right carotid artery occlusion followed by exposure to $8 \% \mathrm{O}_{2}$ inhalation for $2 \mathrm{~h}$. Twenty-four hours after HI, rats received either saline solution or HUCB cells i.v. After 3 wk, rats were assessed using a Morris Water Maze and four motor tests. Subsequently, rats were killed for histologic, immunohistochemical, and polymerase chain reaction (PCR) analyses. HI rats showed significant spatial memory deficits and a volumetric decrease in the hemisphere ipsilateral to arterial occlusion. These deficits and decreases were not significantly attenuated by the injection of HUCB cells. Moreover, immunofluorescence and PCR analysis revealed few HUCB cells located in rat brain. Intravenous administration of HUCB cells requires optimization to achieve improved therapeutic outcomes in neonatal hypoxic-ischemic injury. (Pediatr Res 65: 631-635, 2009)
\end{abstract}

$\mathrm{N}^{\mathrm{en}}$ eonatal hypoxia-ischemia (HI) is a major cause of mortality and morbidity in infants and occurs in approximately 2-4 per 1000 full-term births. Between 20 and 50\% of asphyxiated newborns with hypoxic-ischemic encephalopathy die within the neonatal period, and up to $25 \%$ of the survivors will exhibit neurodevelopment morbidity, such as cerebral palsy, mental retardation, and epilepsy. The most widely used and accepted animal model of neonatal $\mathrm{HI}$ is the Levine method as modified by Rice et al. (1), which represents a useful tool to study long-term effects of neuroprotective strategies in behavioral changes, especially in learning and memory tasks (2). Although promising neuroprotective strategies have been studied in animal models and clinical trials, current management techniques have reached only limited success (3).

Human umbilical cord blood (HUCB), is rich in adult stem cells and seems to be a potential source for transplantation, especially for perinatal neuronal repair. Studies have shown behavioral and neurologic recovery in stroke (4-7) and HIinsulted animals $(8,9)$ that received i.v. injection of HUCB,

Received October 2, 2008; accepted January 25, 2009.

Correspondence: Jaderson Costa Dacosta, M.D., Ph.D., Laboratório de Neurociências, Instituto de Pesquisas Biomédicas e Instituto do Cérebro, PUCRS, Av. Ipiranga 6690/ 220, 90610-000, Porto Alegre, RS, Brazil; e-mail: jcc@pucrs.br

Supported by grants from CNPq, FUNPAR, and Pandurata. indicating that cells migrate toward ischemic regions and cross the blood brain barrier (BBB), especially in acute periods postischemia (10). The i.v. route is less invasive and a safer access to clinical applications when compared with intracerebral delivery. However, very few transplanted cells are found in the brain when delivered intravascularly. Therefore, evidence suggests that these cells increase endogenous mechanisms of brain repair by trophic factor secretion rather than by replacing the damaged tissue $(11,12)$.

The aim of this study was to assess the effects of HUCB cells on spatial memory, motor performance, and brain morphologic changes in 30-d-old rats after neonatal $\mathrm{HI}$ on postnatal d 7. In addition, we tested whether the injected HUCB cells migrate to the injured brain $24 \mathrm{~h}$, and 1 and $3 \mathrm{wk}$ after $\mathrm{HI}$ insult.

\section{METHODS}

Experimental groups. The animals were randomly divided into three experimental groups: A) sham-operated animals $(n=9)$; B) rats infused with saline solution $24 \mathrm{~h}$ after $\mathrm{HI}$ injury ( $\mathrm{HI}+$ saline; $n=10)$; and $\mathrm{C}$ ) rats infused with HUCB cells $24 \mathrm{~h}$ after $\mathrm{HI}$ injury (HI $+\mathrm{HUCB} ; n=15)$. After $3 \mathrm{wk}$, rats were assessed in Morris Water Maze (MWM) and four motor tests. All evaluations were performed by blinded investigators.

Neonatal hypoxia-ischemia model. We used the Levine rat model, modified by Rice et al. (1) for neonatal rats. On postnatal d 7, Wistar rats were briefly anesthetized with halothane, and the right common carotid artery was identified, isolated from the vagus nerve, and permanently occluded with 7.0 surgical silk sutures. The entire surgical procedure was completed within $15 \mathrm{~min}$.

After surgery, animals were put back into their cages and allowed to recover for 2-4 h in the company of their mothers. Rats were then placed for $2 \mathrm{~h}$ in a hypoxia chamber, with constant flow of humidified $8 \%$ oxygen balanced with nitrogen. The environmental temperature was maintained at $37-38^{\circ} \mathrm{C}$.

The sham-operated animals were anesthetized with halothane and exposure of the right common carotid artery without ligation and hypoxia. All experiments were performed in accordance with the Guide for the Care and Use of Laboratory Animals adopted by the National Institutes of Health (USA).

Human umbilical cord blood cell separation procedure and administration. Cord blood collections were obtained ex utero using sterile syringes containing anticoagulant from full-term births of healthy donors. All samples $(n=5)$ were collected after obtaining written informed consent forms.

Blood samples were processed within a range of $24 \mathrm{~h}$ after collection. HUCB was diluted with RPMI medium 1640 (GIBCO, Langley, OK) and this suspension was fractionated on Histopaque density (Sigma ChemicalAldrich) at $400 \mathrm{~g}$ for $30 \mathrm{~min}$ at room temperature. The mononuclear fraction was collected and rinsed twice with phosphate-buffered saline (PBS) contain-

Abbreviations: BBB, blood brain barrier; HI, hypoxia-ischemia; HUCB, human umbilical cord blood; MWM, Morris Water Maze 
ing $1 \%$ of Liquemine (Roche, Swiss). The cell viability was evaluated using the Trypan Blue Stain 0.4\% (GIBCO, Langley, OK) exclusion method. CD $34+$ cells represented, on average, $0.05 \%$ of cord blood mononuclear cells after flow cytometric analysis.

Twenty-four hours after HI, randomly selected rats received i.v. either HUCB cells or saline solution. Using a micropipette with ultrafine tip (diameter $<5 \mu \mathrm{m}$ ) connected to an insulin syringe, we injected $1 \times 10^{7}$ mononuclear cells $(6,8)$ suspended in $100 \mu \mathrm{L}$ total fluid volume into the external jugular vein.

Morris water maze. The spatial memory performance was evaluated $3 \mathrm{wk}$ after HI lesion using an MWM $(13,14)$. The water maze consists of a black circular pool conceptually divided in four equal imaginary quadrants. Two centimeters beneath the surface of the water and hidden from the rat's view was a black circular platform. The water maze was located in a well-lit white room with several spatial cues.

Training on spatial version of the MWM was carried out over 5 consecutive days. On each day, rats received four training trials in which the hidden platform was kept in a constant location. The mean latency to find the platform was measured for individual animals on each day.

A different starting location was used in each trial, which consisted of a swim followed by a $30 \mathrm{~s}$ platform sit. Rats that did not find the platform within $60 \mathrm{~s}$ were guided to it by the experimenter. To assess long-term memory, $24 \mathrm{~h}$ after the final trial, the platform was removed from the maze and the parameter measured was time spent in the target quadrant.

Open-field activity. Rats were placed in a $40 \times 30 \mathrm{~cm}$ wood box and left to explore the arena freely for a 5 -min period. The floor was divided into 12 equal squares by black lines. The number of line crossings, number of rearings, and locomotion time were measured (15).

Cylinder test. Forelimb use was analyzed by videotaping movements of each rat during vertical exploration in a transparent cylinder $(15 \times 30 \mathrm{~cm})$. Each animal was placed in the cylinder and observed for $5 \mathrm{~min}$. The forelimb use asymmetry score was calculated as the percentage of nonimpaired forelimb use subtracted from the percentage of impaired forelimb use (16).

Grid walking test. The rats were placed on a stainless steel grid floor elevated $1 \mathrm{~m}$ above the floor. For 1-min observation period, the total number of steps was counted as well as the number of foot fault errors (15).

Tapered/ledged beam walking test. The beam-walking apparatus consisted of a tapered wooden beam with ledges on each side to permit foot faults without falling. The end of the beam was connected to a black box. A bright light was placed above the start point to motivate the rats to traverse the beam. The score for each trial was calculated as follows: [(vertical slips $\times 0.5+$ horizontal slips)/(steps + vertical slips + horizontal slips)] $\times 100(17)$.

Morphologic study. The animals were deeply anesthetized with thiopental sodium $(0.1 \mathrm{~mL} / 100 \mathrm{~g}$, i.p. $)$ and perfused transcardially with saline followed with $4 \%$ paraformaldehyde. The brains were removed from the skull and stored in the same solution for $24 \mathrm{~h}$. Coronal sections of the brain $(50 \mu \mathrm{m})$ were cut using a cryostat (Shandon, United Kingdom), with $250 \mu \mathrm{m}$ intervals, and stained with cresyl violet using the Nissl method. Digitized images of cross-sectional areas were obtained with a video camera installed in an Olympus BX40 microscope, interfaced by a software (Image Pro-Plus 6.1, Media Cybernetics) run on a personal computer. Images of the hemispheres were displayed onto a high-resolution video monitor and its boundaries were outlined for area measurements in accordance with the Paxinos and Watson atlas (18).

The Cavalieri method was used to estimate the hemispheric volumes $\left(\mathrm{mm}^{3}\right)$ by summation of areas multiplied by the distance between sections. The cross-sectional area of the hemisphere was obtained outlining edges of each hemisphere. Volume estimation was performed in about 10 sections for each rat $(19,20)$.

Immunofluorescent staining. Rats from the HUCB cell group were killed $24 \mathrm{~h}(n=2)$, and $1(n=2)$ and $3(n=2)$ wk after neonatal HI injury. Brains were removed from the skulls and frozen in liquid nitrogen $\left(-70^{\circ} \mathrm{C}\right)$. Coronal sections $(15 \mu \mathrm{m})$ were obtained using a cryostat at $-20^{\circ} \mathrm{C}$ and postfixed in acetone. To identify grafted human cells, sections were incubated with mouse antihuman nuclear monoclonal antibody (MAb) (MAb-1281; dilution 1:100; Chemicon International) overnight at $4^{\circ} \mathrm{C}$. After washing in $0.1 \mathrm{M}$ PBS, FITC (dilution 1:100; Novocastra Laboratories) was added and incubated at room temperature in the absence of light for $1 \mathrm{~h}$. To specifically stain the nuclei with blue fluorescence, 4', 6-diamino-2-phenylindole (DAPI, Santa Cruz Biotechnology) was used. To detect human cells in rat brain, double-stained sections were examined to identify those MAb-1281 positive cells that colabeled with DAPI, as previously described (6).

Reactivity of these antibodies with human cells had been confirmed in positive samples and negative control sections were processed as per the experimental tissue, but the primary or secondary antibodies were omitted. Slides were examined qualitatively in a Nikon Eclipse E800 fluorescence microscope coupled to a Pro-Series High Performance CCD camera and Image Pro Plus Software 6.1 (Media Cybernetics, Bethesda, MD).
Polymerase chain reaction analysis. DNA was obtained from the brain and other organs $24 \mathrm{~h}$, and 1 and 3 wk after HUCB cell injection using Trizol Reagent (Carlsbad, CA). To evaluate HUCB cells migration, polymerase chain reaction (PCR) analysis for human $\beta$-actin gene was performed using primers (direct 5'-CCTCATGAAGATCCTCAC-3' ${ }^{\prime}$, and reverse $5^{\prime}$ TGGAGAAGAGCTACAAGC-3'), which results in a 161 bp amplicon. Amplicons were analyzed after electrophoresis on $2 \%$ agarose gel and visualized with ethidium bromide staining.

Statistical analysis. The sample size (nine animals per group) was calculated to provide more than $80 \%$ power to detect a reduction in behavioral outcomes of $40 \%$ between the groups.

Variables with normal distribution were presented as means \pm SEM. Comparisons between the groups were analyzed using one-way analysis of variance (ANOVA) followed by Tukey's test, and behavioral performance on the training day was analyzed using a two-way ANOVA followed by the Bonferroni test. Variables with abnormal distribution were presented as median (minimum and maximum), and the Kruskal-Wallis test was used after Dunn's comparison. Data were considered significantly different if $p<0.05$.

\section{RESULTS}

Eight rats died during different steps of the experiment (19\%). These animals were not considered in the final sample size.

To determine whether i.v. administration of HUCB cells can improve cognitive deficits, 30 -d-old rats were trained in the spatial version of the MWM. Except on d 1, two-way ANOVA revealed significant differences between the experimental groups during the training period. As shown in Figure $1 A$, the mean latency of the second to fifth day was shorter in sham-operated rats when compared with the saline and HUCB cell groups, indicating that $\mathrm{HI}$ impaired memory performance in the injured animals. During this test, rats that had received i.v. HUCB cells $24 \mathrm{~h}$ after $\mathrm{HI}$ did not present a statistically significant shorter latency to find the platform on the $\mathrm{d} 2$ to $\mathrm{d} 4$.

Analysis of the probe trials (Fig. $1 B$ ) using one-way ANOVA followed by the Tukey test also showed that the sham-operated group spent significantly more time in the target quadrant when compared with $\mathrm{HI}$ animals treated with HUCB cells $(p=0.008)$ and saline $(p<0.001)$. No statistically significant difference was found between the transplanted HI rats and the saline group in terms of the latency to swim over the previous location of the escape platform $(p=0.25)$.

To analyze the motor performance of the experimental groups, we performed four motor tests. Table 1 shows that open-field activity, cylinder, grid walking, and ledged beam walking tests did not reveal significant differences between the HUCB, saline, and sham-operated groups.
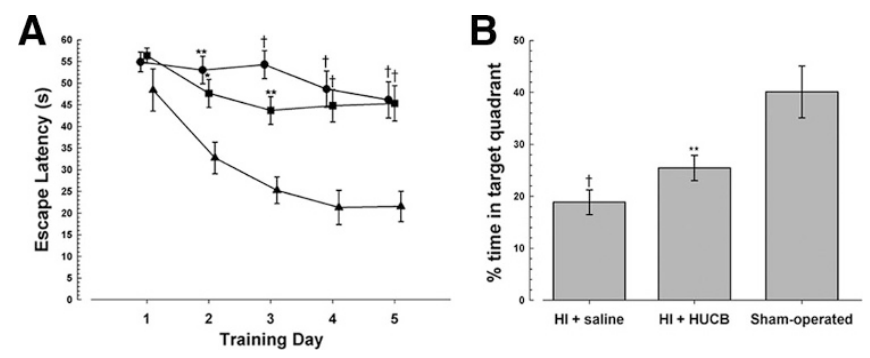

Figure 1. MWM performed 3 wk after HI injury. (A) Mean escape latency during the $5 \mathrm{~d}$ of training for sham-operated $(\mathbf{\Lambda} ; n=9)$, HI + saline $(\boldsymbol{\bullet} ; n=$ $10)$ and HI + HUCB $(\boldsymbol{\square} ; n=15)$ rats. (B) Mean percentage of time spent in the target quadrant during a 60 -s probe test in the absence of the escape platform carried out $24 \mathrm{~h}$ after the fifth training day for rats that received saline or HUCB cells as in A. Post hoc test shows HI + saline $v s$. sham: $p<$ 0.001; HI + HUCB vs. sham: $p=0.008$; HI + saline vs. HI + HUCB: $p=$ 0.25 . $* p<0.05 ; * * p<0.01 ; \dagger p<0.001$ vs. sham-operated rats. 
Table 1. Motor performance in three groups within the study

\begin{tabular}{|c|c|c|c|c|}
\hline Test/group & $\mathrm{HI}+\mathrm{HUCB}$ & $\mathrm{HI}+$ saline & Sham-operated & $p$ \\
\hline Locomotion time (s): mean \pm SEM & $107.09 \pm 5.61$ & $99.75 \pm 5.39$ & $109.13 \pm 4.76$ & 0.44 \\
\hline No. rearing: mean \pm SEM & $31.64 \pm 3.08$ & $35.75 \pm 2.01$ & $29.38 \pm 2.01$ & 0.21 \\
\hline No. crossings: mean \pm SEM & $115.55 \pm 6.55$ & $113.17 \pm 5.50$ & $124.63 \pm 4.47$ & 0.40 \\
\hline Cylinder test (\%): median (minimum-maximum) & $12.90(-2.7$ to 69.23$)$ & $13.17(-7.14$ to 53.85$)$ & $2.94(-1.37$ to 11.32$)$ & 0.06 \\
\hline Grid walking (\%): median (minimum-maximum) & 16.67 (4 to 21.43 ) & 11.24 (7.14 to 21.43$)$ & $5.72(0$ to 33.33$)$ & 0.07 \\
\hline Ledged beam walking $(\%)$ : means \pm SEM & $10.94 \pm 1.01$ & $8.62 \pm 0.59$ & $10.98 \pm 1.47$ & 0.15 \\
\hline
\end{tabular}

Variables with normal distribution are presented as means \pm SEM and are compared using one-way ANOVA. Otherwise, variables are presented as median (minimum and maximum) and are compared using the Kruskal-Wallis test.

We also examined whether HI resulted in morphologic deficits and if i.v. administration of HUCB cells attenuated neuronal loss. The results of the morphologic assessment in animals treated only with saline solution showed that neonatal HI lesion caused a significant decrease in the volume of the hemisphere ipsilateral to carotid occlusion (right) when compared with the contralateral hemisphere $(p<0.001) 3$ wk after injury (Fig. 2A). The group that received HUCB cells also presented significantly reduced volume in the right hemisphere when compared with the left hemisphere $(p<0.01)$. Figure $2 B$ shows that there is no statistically significant difference between the $\mathrm{HI}+$ saline and $\mathrm{HI}$ animals treated with HUCB cells in terms of the relative difference between left and right hemispheric
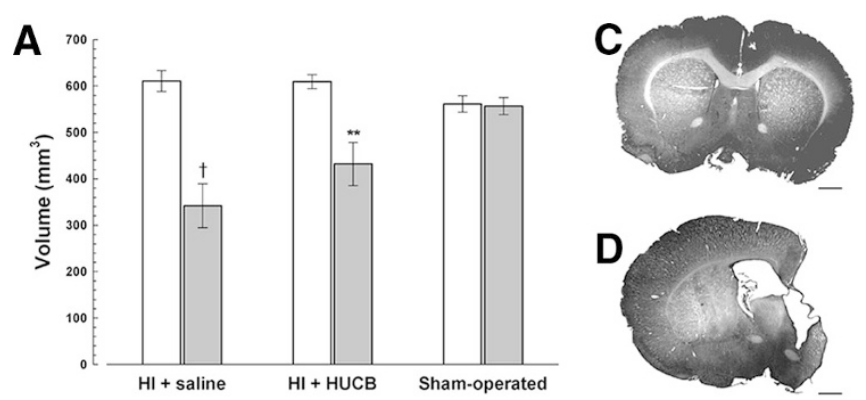

\section{B}
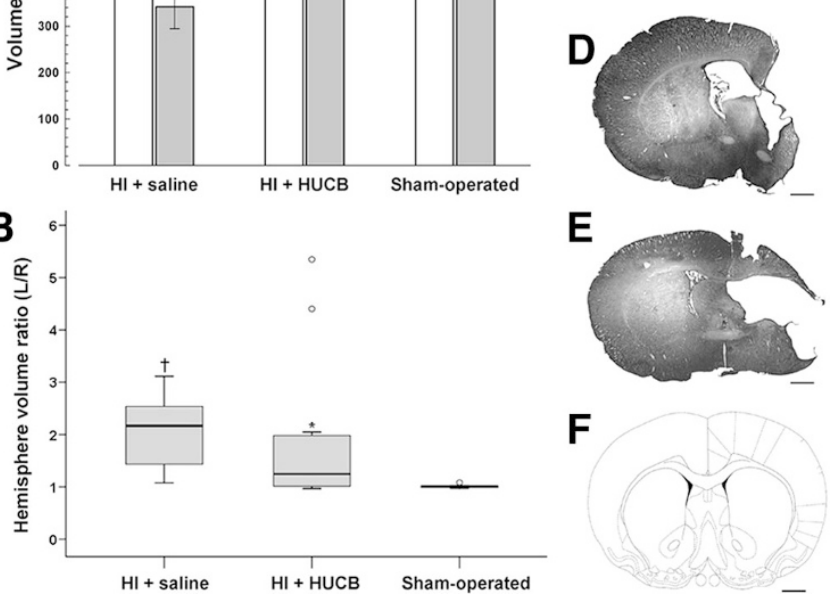

E

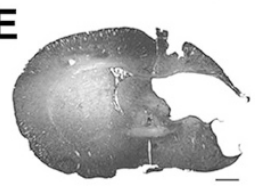

$\mathbf{F}$

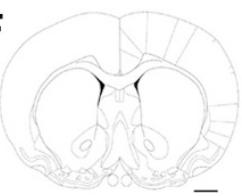

Figure 2. (A) The estimated volumes of brain hemispheres, using the Cavalieri method in sham-operated $(n=9), \mathrm{HI}+$ saline $(n=10)$ and HI + HUCB $(n=15)$ rats $3 \mathrm{wk}$ after $\mathrm{HI}$ injury. There is a significant decrease in the right hemisphere volume (gray columns) in HI + saline $(p<0.001)$ and $\mathrm{HI}+$ HUCB groups ( $p<0.01)$, when compared with the left side (white columns). Data expressed as means \pm SEM. ANOVA was used followed by a Tukey test $(* p<0.05 ; * * p<0.01 ; \dagger p<0.001)(B)$ Hemispheric volume ratio determined by division of the left hemisphere by the right hemisphere, showing a tendency to reduction in HUCB cell group when compared with saline animals. Data are expressed as median (minimum and maximum). Circles represent outliers. Post hoc analysis shows HI + saline $v s$. sham: $p<$ 0.001; HI + HUCB vs. sham: $p=0.02$; HI + saline vs. HI + HUCB: $p=$ 0.095. $(C-F)$ We can observe digitized images of coronal sections of the rat brains stained using the Nissl procedure. (C) Sham-operated. $(D) \mathrm{HI}+$ saline. $(E)$ HI + HUCB. $(F)$ Schematic drawings obtained from Paxinos and Watson's atlas (interaural $9.70 \mathrm{~mm}$; bregma $0.70 \mathrm{~mm}$ ). Calibration bars $=1 \mathrm{~mm}$. volume (hemisphere volume ratio $=$ left hemisphere volume/ right hemisphere volume) $(p=0.095)$.

Qualitative analysis of HUCB cell migration detected few MAb-1281 immunoreactive cells in either the ipsilateral or contralateral hemispheres $24 \mathrm{~h}$, and 1 and 3 wk after HI injury (Fig. 3A-I). To confirm the distribution of HUCB cells after i.v. administration, PCR analysis using human $\beta$-actin was performed (Fig. 3J). The expression of human $\beta$-actin was detected in the ipsilateral and contralateral hemispheres $24 \mathrm{~h}$, and 1 and 3 -wk postinjury.

\section{DISCUSSION}

This study showed that neonatal HI brain injury induced significant long-term spatial memory deficits and extensive brain hemisphere atrophy. In those animals that received i.v. administration of HUCB cells $24 \mathrm{~h}$ after HI induction, the degree of behavioral and morphologic impairment was not significantly reduced. Importantly, the administration of human cells did not worsen the outcomes in HI rats.

As with other investigations, our study showed that, in spite of severe brain damage, motor function tests were insufficiently sensitive to detect neuromotor alterations in all $\mathrm{HI}$ rats (2). In contrast to human neonates, pups that underwent HI injury did not show obvious postural or locomotor abnormalities due to a higher degree of plasticity in immature rat brain (21). However, studies have demonstrated that injured brain regions required for memory and learning processing result in significantly decreased spatial memory (2). Our results showed that the MWM test was sensitive to brain damage in neonatal HI rats.

Several groups have reported that HUCB cells delivered either intracerebrally or i.v. dramatically enhance functional recovery after ischemic injury in adult rats. The mechanisms behind such reported neuroprotection are not known, but may include cytokines and trophic factors produced by HUCB cells $(6,7,22-24)$. However, some authors do not confirm these results (25).

Although there are few reported studies on the use of cellular therapy in neonatal brain damage models, there is a wide range of methods used $(8,9,26,27)$. Ma et al. used a HI mouse model similar to ours when studying the effect of stem cell transplantation. They showed that the transplanted cells significantly improved the learning and memory deficits 8 mo posttransplantation. However, this study used mice embryonic stem cells injected directly into the lesion site (26).

The route of delivery may contribute to contrasting data. To date, no study had used the acute transplant ( $24 \mathrm{~h}$ after insult) 

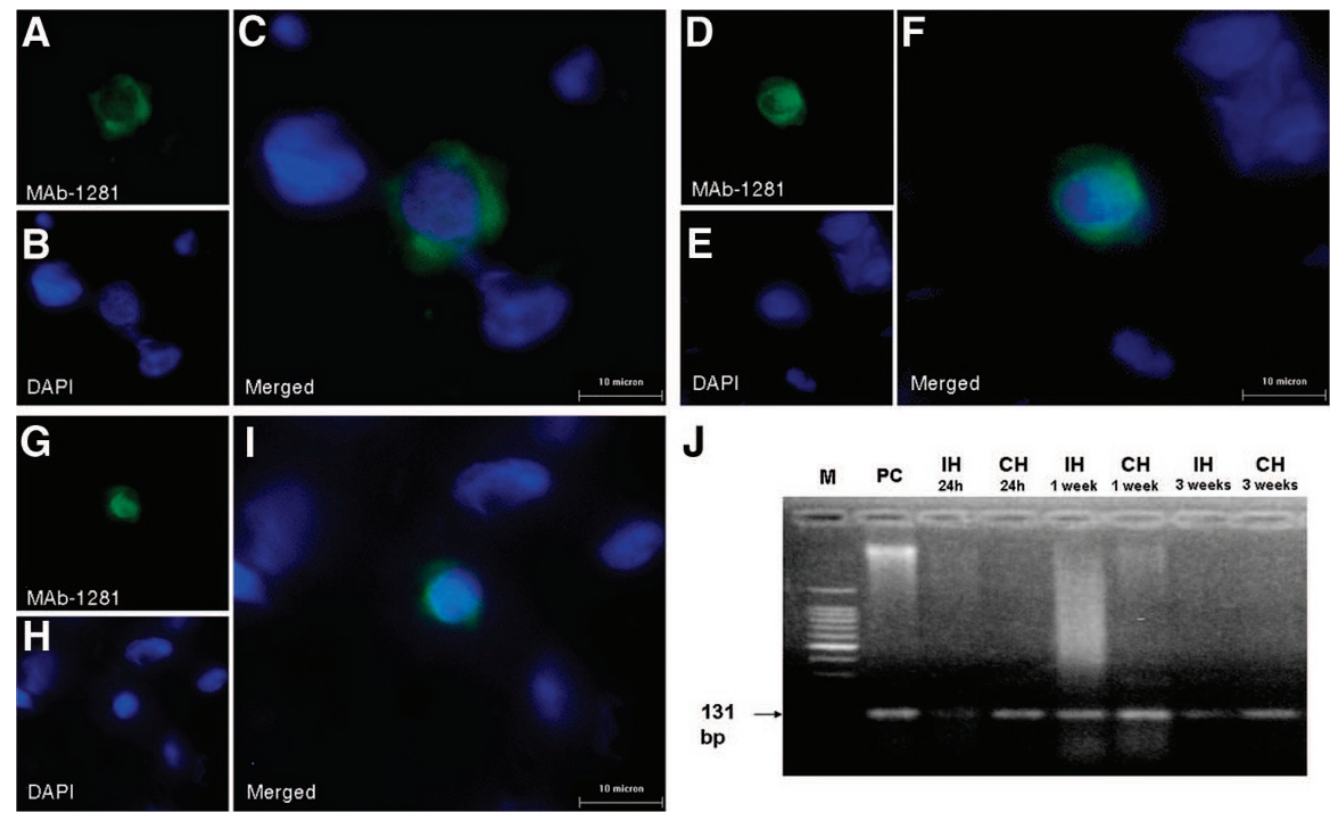
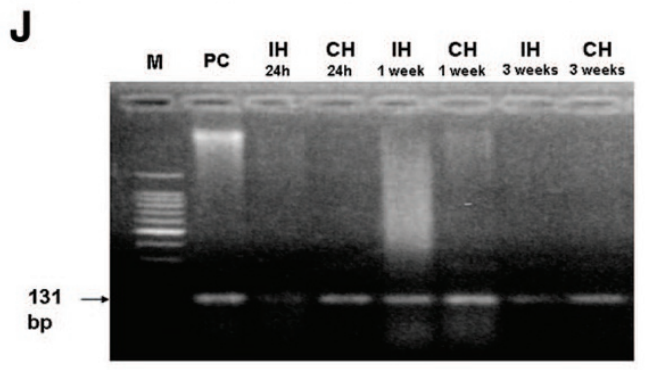

Figure 3. $(A-I)$ Digitized images of rat brain showing the immunoreaction to human nuclei antibody (MAb1281). Use of immunofluorescence FITC (green) shows few MAb-1281 immunoreactive cells in rat brain at (A) $24 \mathrm{~h}$, and $(D) 1$ and $(G) 3 \mathrm{wk}$ after HI injury. $(B, E, H)$ Nuclei visualized by DAPI staining (blue). ( $C$, $F, I)$ Colocalization of immunofluorescent labels DAPI and MAb-1281 was observed. $(J)$ Representative PCR analysis results for human $\beta$-actin of rats after 24-h, and 1- and 3-wk postinjury. Positive control $(\mathrm{PC})=\mathrm{hu}-$ man DNA extracted from human hippocampus. IH, ipsilateral hemisphere; $\mathrm{CH}$, contralateral hemisphere. of adult stem cells into neonatal rat by i.v. delivery. Intravenous administration has the advantage of being less invasive but raises the problem of cell homing to organs and target site (11). Yasuhara et al. (9) demonstrated that both intracerebral and i.v. injection of multipotent adult progenitor cells resulted in behavioral improvement in HI rats although the percentage of graft survival was small. However, Borlongan et al. (28) showed that in contrast with intracerebral transplantation, i.v. delivery of bone marrow stem cells produced only limited functional effects in stroke rats. In our study, the nonsignificant functional recovery could also be explained by the small number of MAb1281-positive cells found in rat brain.

We chose to administer the cells $24 \mathrm{~h}$ after injury to target acute ischemic processes, such as the inflammation and BBB opening. The optimal time for transplantation after injury is also a critical factor in initiating the repair process. Acute delivery of cells will be critical once the ischemic brain elicits a strong inflammatory response about $24 \mathrm{~h}$ postinsult $(10,22,28)$. Also, the BBB may be more accessible at $24-72 \mathrm{~h}$ postischemia and combined opening of the BBB and the high expression of chemokines could have facilitated the present mononuclear cell graft migration toward and survival within the ischemic area (29). However, Borlongan et al. reported that BBB opening produced by middle cerebral artery occlusion was not permissive enough to allow CNS entry of graft-derived trophic factors. In that study, improved behavioral functions were observed only in rats treated with cord blood stem cells associated with mannitol (4). Previously, we evaluated the BBB permeability in five rats $24 \mathrm{~h}$ after HI. Mild leakage was observed in these animals after trypan blue injection (data not shown).

Our morphologic analyses showed that neonatal HI resulted in an extensive infarcted area and that i.v. injection of HUCB cells was unable to significantly reduce the severity of the morphologic damage. We used a dose of $1 \times 10^{7}$ HUCB cells in accordance with previous studies (8). However, few reports about stem cell therapy in brain damage have studied specific dose range (6).

Our study has some limitations. Seven-day-old rats are considered to be similar to human newborns with regard to brain maturation, and the animal is highly suitable for longterm behavioral evaluations. However, Levine rat model results in variable degrees of damage due to individual differences in brain susceptibility among animals $(2,30)$. We hypothesized that the large extension of the hemispheric brain lesion obtained in our study could have contributed to the fact that we did not observe repair after the infusion of $1 \times 10^{7}$ HUCB cells. It is possible that rats with smaller brain injury will have a different response to i.v. injection of HUCB cells.

Only a low number of HUCB cells were detected in rat brain $24 \mathrm{~h}$, and 1 and $3 \mathrm{wk}$ after neonatal HI, as reported in other investigations $(4,6,8,22)$. Despite controversies, immunosuppressive treatment may be a key determinant for homing of HUCB cells i.v. infused into rats (31). Several investigations suggest that $\mathrm{T}$ cell-mediated immune reaction plays a significant role in graft rejection and that interspecies incompatibility contributes significantly to phagocytosis of xenogeneic cells (32). Although xenoreactivity to human mesenchymal stem cells transplanted into infarcted rat myocardium has been demonstrated (33), these findings contrast with the results of Saito et al. (34). Indeed, xenotransplantation of human bone marrow stem cells ameliorates neurologic deficits after grafting into ischemic brain of rats (35). Also, the results obtained by Chen et al. (22) with HUCB cells in rats with stroke suggest an immunologic tolerance to human cells. Although we do not have evidence of host immune response to the transplanted cells, the administration of human cells could have played a role in the negative results obtained in this study.

In addition, the unilateral carotid artery permanent occlusion results in reduction of cerebral blood flow within the various structures of the hemisphere ipsilateral to the vascular occlusion (30). We speculated that low perfusion in distal field 
regions may hamper migration of $\mathrm{HUCB}$ cells to injured structures, which could also explain our immunohistochemical, behavioral, and morphologic results.

In conclusion, this study suggests that, according to our experimental design, HI neonatal rats with severe brain damage that received i.v. administration of HUCB cells showed nonsignificant improvement to functional and morphologic outcomes. Aspects such as dose, timing, peripheral route of HUCB cell delivery, immunosuppression, and use of associated therapies need to be investigated in depth before cellular therapy is clinically applied to optimize neuroprotection and, consequently, neurobehavioral outcomes.

Acknowledgments. The authors thank Tiago Giuliani for assistance with the immunohistochemical procedure, Dr. Mário Wagner for help in the statistical analysis, and Dr. Martin Cammarota for critical reading of this manuscript.

\section{REFERENCES}

1. Rice JE, Vannucci RC, Brierley JB 1981 The influence of immaturity on hypoxicischemic brain damage in the rat. Ann Neurol 9:131-141

2. Golan H, Huleihel M 2006 The effect of prenatal hypoxia on brain development: shortand long-term consequences demonstrated in rodent models. Dev Sci 9:338-349

3. Vannucci RC 2000 Hypoxic-ischemic encephalopathy. Am J Perinatol 17:113-120

4. Borlongan CV, Hadman M, Sanberg CD, Sanberg PR 2004 Central nervous system entry of peripherally injected umbilical cord blood cells is not required for neuroprotection in stroke. Stroke 35:2385-2389

5. Chen N, Hudson JE, Walczak P, Misiuta I, Garbuzova-Davis S, Jiang L, SanchezRamos J, Sanberg PR, Zigova T, Willing AE 2005 Human umbilical cord blood progenitors: the potential of these hematopoietic cells to become neural. Stem Cells 23:1560-1570

6. Vendrame M, Cassady J, Newcomb J, Butler T, Pennypacker KR, Zigova T, Sanberg CD, Sanberg PR, Willing AE 2004 Infusion of human umbilical cord blood cells in a rat model of stroke dose-dependently rescues behavioral deficits and reduces infarct volume. Stroke 35:2390-2395

7. Vendrame M, Gemma C, de Mesquita D, Collier L, Bickford PC, Sanberg CD, Sanberg PR, Pennypacker KR, Willing AE 2005 Anti-inflammatory effects of human cord blood cells in a rat model of stroke. Stem Cells Dev 14:595-604

8. Meier C, Middelanis J, Wasielewski B, Neuhoff S, Roth-Haerer A, Gantert M, Dinse HR, Dermietzel R, Jensen A 2006 Spastic paresis after perinatal brain damage in rats is reduced by human cord blood mononuclear cells. Pediatr Res 59:244-249

9. Yasuhara T, Hara K, Maki M, Mays RW, Deans RJ, Hess DC, Carroll JE, Borlongan CV 2008 Intravenous grafts recapitulate the neurorestoration afforded by intracerebrally delivered multipotent adult progenitor cells in neonatal hypoxic-ischemic rats. J Cereb Blood Flow Metab 28:1804-1810

10. Sanberg PR, Willing AE, Garbuzova-Davis S, Saporta S, Liu G, Sanberg CD, Bickford PC, Klasko SK, El-Badri NS 2005 Umbilical cord blood-derived stem cells and brain repair. Ann N Y Acad Sci 1049:67-83

11. Bliss T, Guzman R, Daadi M, Steinberg GK 2007 Cell transplantation therapy for stroke. Stroke 38:817-826

12. Guzman R, Choi R, Gera A, De Los Angeles A, Andres RH, Steinberg GK 2008 Intravascular cell replacement therapy for stroke. Neurosurg Focus 24:E15

13. Kumral A, Uysal N, Tugyan K, Sonmez A, Yilmaz O, Gokmen N, Kiray M, Genc S, Duman N, Koroglu TF, Ozkan H, Genc K 2004 Erythropoietin improves long-term spatial memory deficits and brain injury following neonatal hypoxiaischemia in rats. Behav Brain Res 153:77-86
14. Rossato JI, Bevilaqua LR, Myskiw JC, Medina JH, Izquierdo I, Cammarota M 2007 On the role of hippocampal protein synthesis in the consolidation and reconsolidation of object recognition memory. Learn Mem 14:36-46

15. Lubics A, Reglodi D, Tamas A, Kiss P, Szalai M, Szalontay L, Lengvari I 2005 Neurological reflexes and early motor behavior in rats subjected to neonatal hypoxicischemic injury. Behav Brain Res 157:157-165

16. Schallert T, Fleming SM, Leasure JL, Tillerson JL, Bland ST 2000 CNS plasticity and assessment of forelimb sensorimotor outcome in unilateral rat models of stroke, cortical ablation, parkinsonism and spinal cord injury. Neuropharmacology 39:777-787

17. Fujimoto ST, Longhi L, Saatman KE, Conte V, Stocchetti N, McIntosh TK 2004 Motor and cognitive function evaluation following experimental traumatic brain injury. Neurosci Biobehav Rev 28:365-378

18. Paxinos G, Watson C 1986 The Rat Brain in Stereotaxic Coordinates. Academic Press, Sydney

19. Avendano C, Roda JM, Carceller F, Diez-Tejedor E 1995 Morphometric study of focal cerebral ischemia in rats: a stereological evaluation. Brain Res 673:83-92

20. Rodrigues AL, Arteni NS, Abel C, Zylbersztejn D, Chazan R, Viola G, Xavier L, Achaval M, Netto CA 2004 Tactile stimulation and maternal separation prevent hippocampal damage in rats submitted to neonatal hypoxia-ischemia. Brain Res 1002:94-99

21. Yager JY, Wright S, Armstrong EA, Jahraus CM, Saucier DM 2006 The influence of aging on recovery following ischemic brain damage. Behav Brain Res 173:171180

22. Chen J, Sanberg PR, Li Y, Wang L, Lu M, Willing AE, Sanchez-Ramos J, Chopp M 2001 Intravenous administration of human umbilical cord blood reduces behavioral deficits after stroke in rats. Stroke 32:2682-2688

23. Lu D, Sanberg PR, Mahmood A, Li Y, Wang L, Sanchez-Ramos J, Chopp M 2002 Intravenous administration of human umbilical cord blood reduces neurological deficit in the rat after traumatic brain injury. Cell Transplant 11:275-281

24. Willing AE, Lixian J, Milliken M, Poulos S, Zigova T, Song S, Hart C, SanchezRamos J, Sanberg PR 2003 Intravenous versus intrastriatal cord blood administration in a rodent model of stroke. J Neurosci Res 73:296-307

25. Makinen S, Kekarainen T, Nystedt J, Liimatainen T, Huhtala T, Narvanen A, Laine J, Jolkkonen J 2006 Human umbilical cord blood cells do not improve sensorimotor or cognitive outcome following transient middle cerebral artery occlusion in rats. Brain Res 1123:207-215

26. Ma J, Wang Y, Yang J, Yang M, Chang KA, Zhang L, Jiang F, Li Y, Zhang Z, Heo C, Suh YH 2007 Treatment of hypoxic-ischemic encephalopathy in mouse by transplantation of embryonic stem cell-derived cells. Neurochem Int 51:57-65

27. Yasuhara T, Matsukawa N, Yu G, Xu L, Mays RW, Kovach J, Deans RJ, Hess DC, Carroll JE, Borlongan CV 2006 Behavioral and histological characterization of intrahippocampal grafts of human bone marrow-derived multipotent progenitor cells in neonatal rats with hypoxic-ischemic injury. Cell Transplant 15:231-238

28. Borlongan CV, Evans A, Yu G, Hess DC 2005 Limitations of intravenous human bone marrow CD133+ cell grafts in stroke rats. Brain Res 1048:116-122

29. Neumann H 2006 Microglia: a cellular vehicle for CNS gene therapy. J Clin Invest 116:2857-2860

30. Vannucci RC, Vannucci SJ 2005 Perinatal hypoxic-ischemic brain damage: evolution of an animal model. Dev Neurosci 27:81-86

31. Irons H, Lind JG, Wakade CG, Yu G, Hadman M, Carroll J, Hess DC, Borlongan CV 2004 Intracerebral xenotransplantation of GFP mouse bone marrow stromal cells in intact and stroke rat brain: graft survival and immunologic response. Cell Transplant 13:283-294

32. Wennersten A, Holmin S, Al Nimer F, Meijer X, Wahlberg LU, Mathiesen T 2006 Sustained survival of xenografted human neural stem/progenitor cells in experimental brain trauma despite discontinuation of immunosuppression. Exp Neurol 199:339-347

33. Grinnemo KH, Mansson A, Dellgren G, Klingberg D, Wardell E, Drvota V, Tammik C, Holgersson J, Ringden O, Sylven C, Le Blanc K 2004 Xenoreactivity and engraftment of human mesenchymal stem cells transplanted into infarcted rat myocardium. J Thorac Cardiovasc Surg 127:1293-1300

34. Saito T, Kuang JQ, Bittira B, Al-Khaldi A, Chiu RC 2002 Xenotransplant cardiac chimera: immune tolerance of adult stem cells. Ann Thorac Surg 74:19-24

35. Zhao LR, Duan WM, Reyes M, Keene CD, Verfaillie CM, Low WC 2002 Human bone marrow stem cells exhibit neural phenotypes and ameliorate neurological deficits after grafting into the ischemic brain of rats. Exp Neurol 174:11-20 